\title{
Cemented or cementless total knee arthroplasty?
}

\section{Comparative results of 200 cases at a minimum follow-up of 11 years}

\author{
Jean-Louis Prudhon ${ }^{1}$ and Régis Verdier ${ }^{2}$ \\ ${ }^{1}$ Centre ostéo-articulaire, 5 rue Raoul Blanchard, 38000 Grenoble, France \\ 2 Groupe Lépine, 175 rue Jacquard, CS 50307, 69727 Genay Cedex, France
}

Received 14 July 2017, Accepted 21 August 2017, Published online 12 December 2017

\begin{abstract}
Introduction: Since 1996 we have been using cementless fixation with hydroxyapatite (HA) coating. The purpose of this paper is to compare survivorship of a series of 100 cemented Total Knee Arthroplasty (TKA) to a similar series of 100 cementless with a follow up of 11-16 years.

Material methods: Both TKA are mobile bearing total knee postero-stabilized. They can be used with cement or without cement. Among 1030 New Wave TKATM implanted from 2002 to 2015 we have identified 100 cemented TKAs and 100 cementless TKAs. All these cases were primary replacement. Differences in survival probability were determined using log-rank test.

Results: Survival probabilities at 11 years of follow-up were: Cemented group: 90.2\% CI95\% [81.9-94.8]; Cementless group: 95.4\% CI95\% [88.1-98.2]. Comparison between both group showed significant difference, $p=0.32$. Discussion: The advantages of cementless TKA are bone stock preservation, cement debris protection and the potential to achieve biologic fixation. Cementless implants rely on a porous or roughened surface to facilitate bone formation. HA has been shown to accelerate bone integration and to decrease micro motion of the components and to increase fixation. With a survival probability of $90.2 \%$ (cemented version) and $95.4 \%$ (cementless version), this total knee prosthesis performs as intended in primary total knee arthroplasty. No statistical differences could be found between cemented and cementless implants.
\end{abstract}

Key words: Total knee arthroplasty, Cemented, Cementless, Comparative series, Hydroxyapatite.

\section{Introduction - background}

Total knee arthroplasty (TKA) is a reliable procedure to treat severe cartilage disease of the knee. Primary osteoarthritis (OA) is the main cause but cartilage destruction may occur after a traumatic event such as a ligament injury or an articular fracture. The frontal deviation of the lower limb is the main risk factor for degenerative changes. Obesity, gender, activity level and age are also well identified as risk factors. The destruction resulting from rheumatoid arthritis is rare but it affects a young population who have severe multiple joint involvement. The TKA outcomes are generally good with a mean survivorship of $90 \%$ at 10 years $[1,2]$. Over three decades improvements have been proposed concerning implant design, surgical techniques, as well as pain management and evaluation of outcome. Regarding implant fixation, the most common method to secure immediate and long-term fixation

\footnotetext{
*Corresponding author: jean-louis.prudhon@wanadoo.fr
}

is dedicated to a cementing technique. In 1980 the first generation of cementless implants [PCA (porous coated Howmedica)] was introduced. Hungerford and co-workers [3-5] published the first clinical results with mid-term results similar to those of the cemented prostheses. Even though the fixation process was much different to the contemporary design, most of the TKA implants over the world are currently cemented.

Since 1996 we have been using cementless fixation with hydroxyapatite (HA) coating as proposed by Epinette and Manley [6].

The purpose of this paper is to compare a series of 100 cemented New Wave TKA $^{\mathrm{TM}}$ (Groupe Lépine, Genay, France) to a similar series of 100 cementless New Wave TKA ${ }^{\mathrm{TM}}$ with a follow-up of 11-16 years and:

1. to analyse complications and reasons for revision (major or minor revision),

2. to report on survival rate at 10 years. 


\section{Materials and methods}

\section{Implant characteristics}

New Wave $\mathrm{TKA}^{\mathrm{TM}}$ is a mobile bearing total knee posterostabilized.

The femoral condyle is symmetric, made of cobalt chromium alloy. It can be used with or without cement. In the cementless version, the inner implant is completely coated under vacuum with a double layer of titanium spray $(120 \mu \mathrm{m})$ covered with HA $(80 \mu \mathrm{m})$ (Figure 1). The condyle has one single rotation centre (Figure 2).

The tibia plate has been designed to get the maximum contact between the host bone and the implant. The stem is perpendicular to the tibia plate in the frontal and sagittal plane. Two types of cementless tibial trays can be used:

1. a regular stem $40 \mathrm{~mm}$ long fully coated with a double layer of titanium spray covered with HA (Figure 1);

2. monoblock long stems $120 \mathrm{~mm}$ long fully coated.

In this study, all the cementless tibial plate were regular stems (40 mm long). The design of the tibial plate and the stem is strictly the same in the cemented and cementless versions. The only difference between cemented and cementless implants is the state of the surface of the implant: fully coated with a double layer of titanium spray covered with HA in cementless tibial plate or roughness $<0.6 \mu$ in the cemented version.

The mobile polyethylene insert (PI) is made of standard ultra high molecular polyethylene weight (UHMPEW), sterilized by ethylene oxide. Its design is specific to allow a total tibio-femoral congruence in the frontal and sagittal plane from full extension to full flexion. It can rotate over the highly polished tibia tray thanks to a $29 \mathrm{~mm}$ long peg freely rotating inside the tibia tray. The stabilizing device is $15.5 \mathrm{~mm}$ high and articulates to the inter-condylar femoral cage (Figure 2).

The patella component is a full polyethylene (PE) domical shape implant, cemented, $8 \mathrm{~mm}$ width with two pegs to ensure bone fixation (Figure 3).

\section{Surgical technique}

The surgical approach is dependent on the type of deformity and ligament contracture. Usually an anteromedial approach is used in varus deformity, while an anterolateral approach in valgus deformity. Anterior tibial tubercle (ATT) osteotomy may be helpful in a stiff knee and/or patella infera to prevent patellar tendon avulsion. Pre-operative patella height assessment is calculated according to a new patella height index as reported by Caton et al. [7] and Prudhon et al. [8]

The ancillary system refers to the intramedullary axis. In our technique, bone cuts are done independently but they can be related to each other. Pre-op planning on full leg length $\mathrm{X}$-ray indicates how much valgus angulation has to be set up on the femoral cutting guide. The posterior cut of the femoral condyles refers to the anterior cortex of the femur. The tibial cut is perpendicular to the diaphysis axis of the tibia in frontal and sagittal plane. The design of the guide allows an extramedullary check to secure the cut.

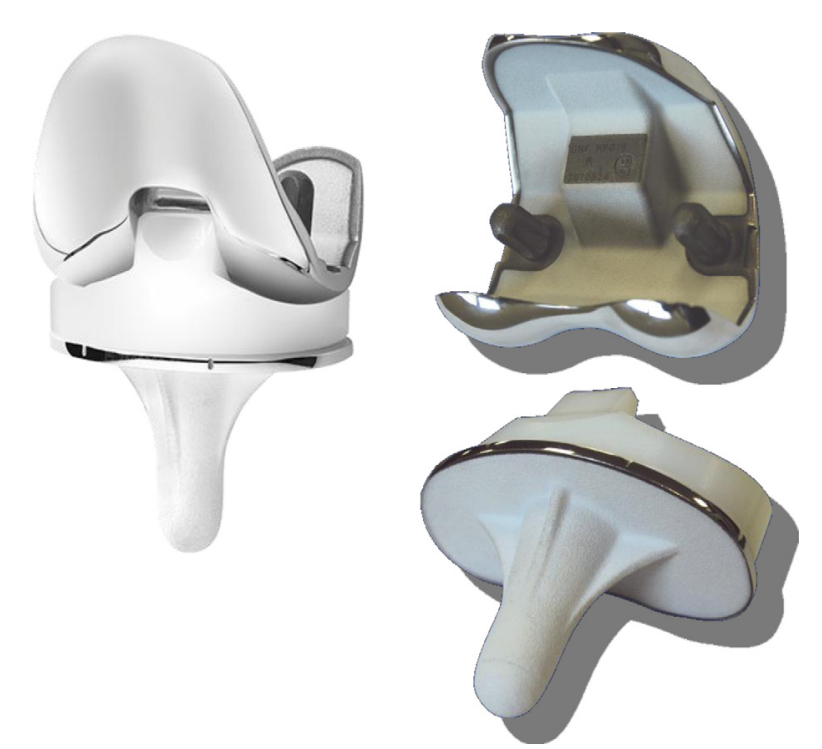

Figure 1. New Wave $\mathrm{TKA}^{\mathrm{TM}}$ implant design, HA coating in cementless version.

The ligament balance is usually done with trial implants.

Care has to be taken with the patella replacement to ensure the right positioning of the implant with respect to the functional centre of the patella.

Implants are cemented with a standard viscosity cement antibiotic loaded (AMINOFIX $1^{\mathrm{TM}}$, Groupe Lépine, Genay, France). In all the knee replacements we have performed with the NEW WAVE ${ }^{\mathrm{TM}}$ implant, whatever the fixation mode, we have replaced the patella with a full PE patellar component cemented with standard viscosity cement antibiotic loaded (AMINOFIX $1^{\mathrm{TM}}$, Groupe Lépine, Genay, France).

Tourniquet was used in all the cases and was released just before cementation for the cemented implants or before implantation for the cementless components.

Full weight bearing and flexion are recommended immediately whatever the implant fixation. Patients are usually discharged in this series at day six and are followed with a clinical and radiographical examination at three months, six months, one year and every two years.

\section{Data collection}

Data are collected on a computerized database (FileMaker Pro). Patient's characteristics such as age at surgery, Charnley classification [9], aetiology, BMI and status (normal, overweight, obese, morbid obesity) functional evaluation, range of motion, surgical details, implant characteristics, pre, post op X-ray analysis, complications and functional outcomes are recorded.

Among the 1030 New Wave TKA ${ }^{\mathrm{TM}}$ implanted from 2002 to 2015 by the single senior surgeon, we have identified 100 cemented New Wave TKA ${ }^{\mathrm{TM}}$ implanted from 2003 to 2005 and 100 cementless New Wave TKA ${ }^{\mathrm{TM}}$ implanted from 2004 to 2006. All these cases were primary replacement. We have excluded TKA after high tibia osteotomy (HTO), revision cases (uni or total knee revisions) or in patients born before 1921 (Figure 4). 


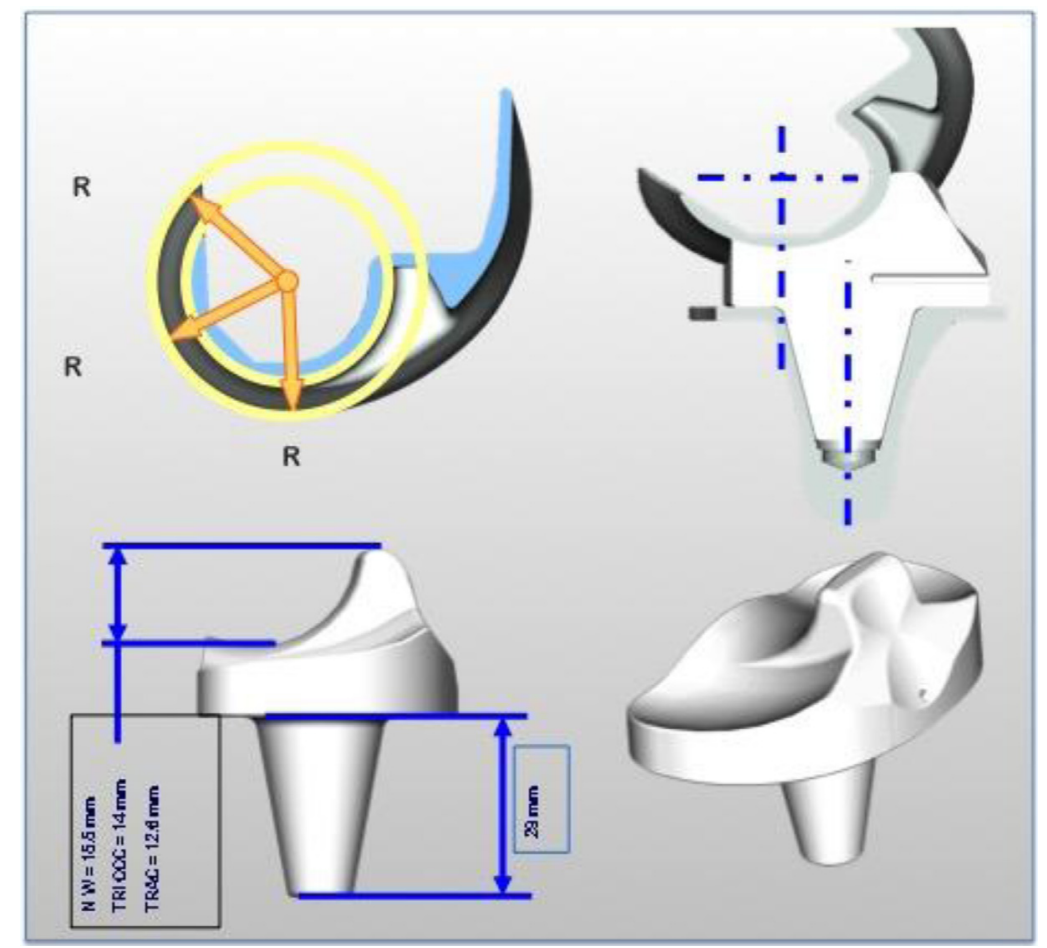

Figure 2. New Wave $\mathrm{TKA}^{\mathrm{TM}}$ implant features.

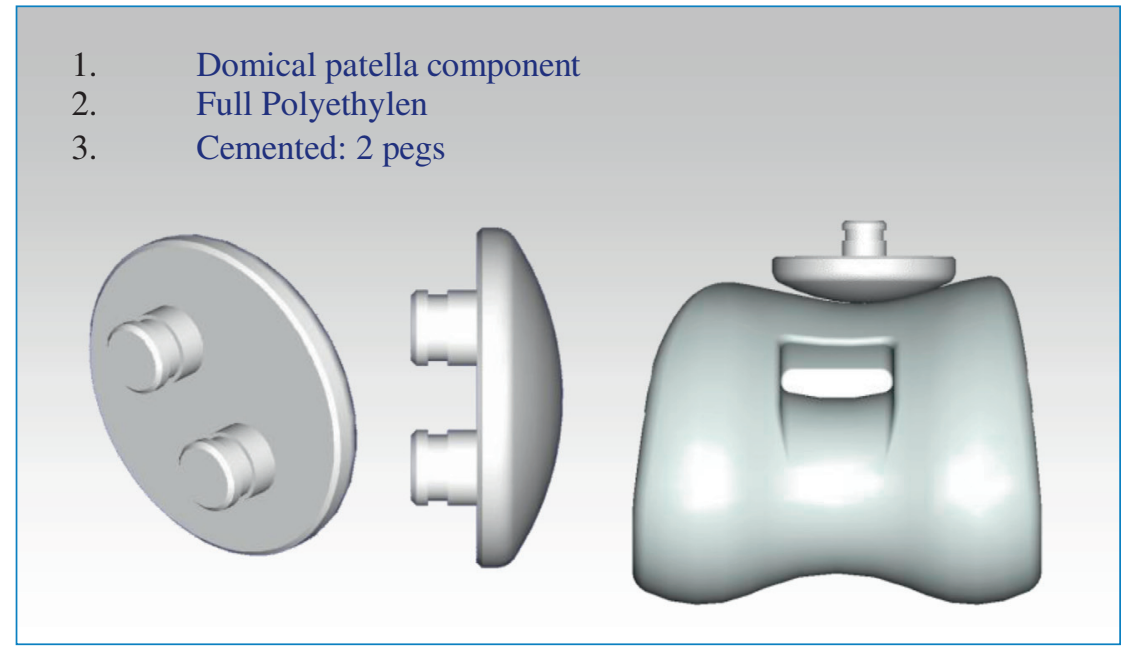

Figure 3. New Wave $\mathrm{TKA}^{\mathrm{TM}}$ patellofemoral joint.

Both populations have been statistically compared in terms of age, gender, aetiology and body weight status in order to obtain the most significantly compared analysis.

\section{Statistical analysis}

Qualitative variables were presented as percentage, quantitative variables as mean and range. These variables were compared between both groups by chi-square or Fisher's exact test. Quantitative variables were compared between both groups by Mann-Whitney test. The survival probability was assessed through the Kaplan-Meier method with 95\% confidence interval. Differences in the survival probability were determined using log-rank test. Statistical analysis was performed with Stata software.

\section{Results}

\section{Cemented series (Table 1)}

Among 338 cemented New Wave TKA ${ }^{\mathrm{TM}}, 100$ cases on 94 patients (59 females) have been included. The mean age 


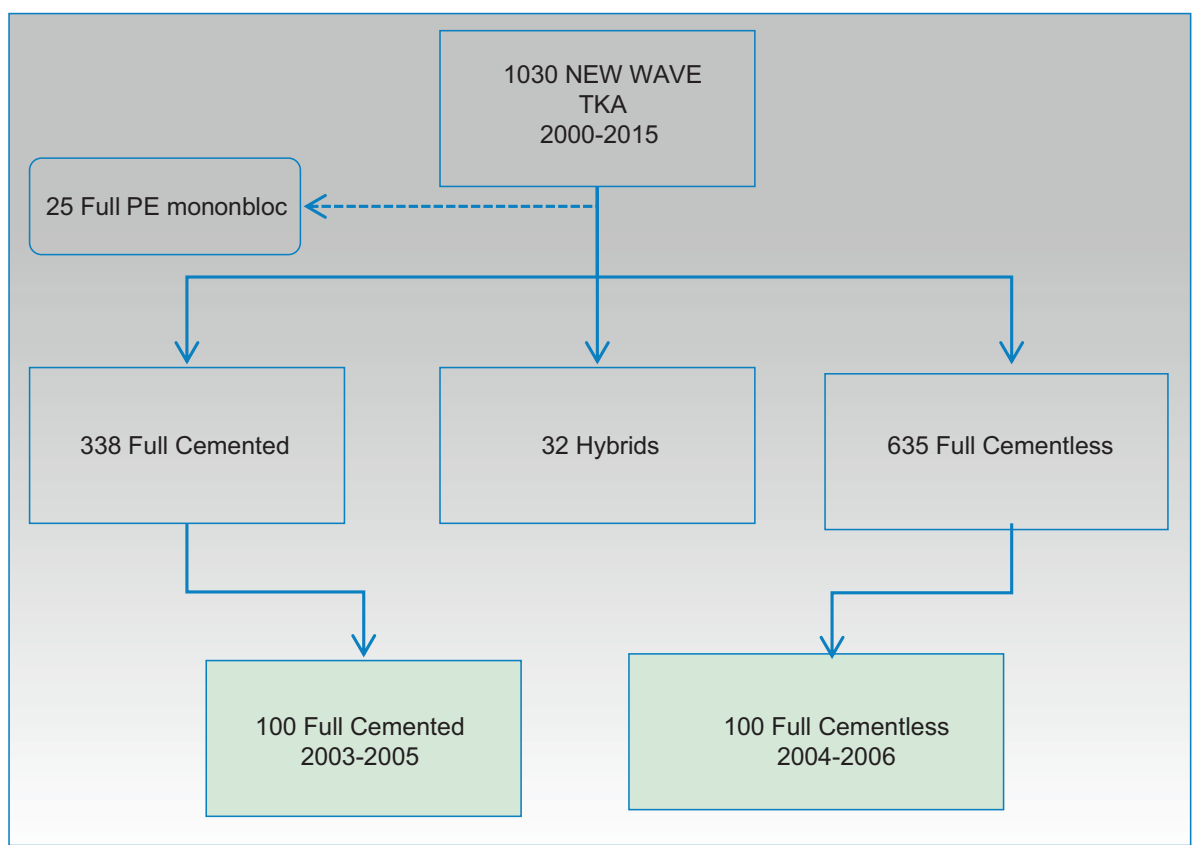

Figure 4. Flow chart of the cases selection.

Table 1. Results of cemented and cementless series.

\begin{tabular}{|c|c|c|c|}
\hline & Cemented & Cementless & $\overline{p \text { value }}$ \\
\hline Number of cases & 100 & 100 & NS \\
\hline Patients & 94 & 95 & \\
\hline Females & 59 & 57 & \\
\hline Age & & & NS \\
\hline Mean age at surgery & 73.16 & 72.25 & \\
\hline Mean follow-up & 13.66 & 12.1 & \\
\hline Previous surgery & & & NS \\
\hline None & 85 & 79 & \\
\hline Meniscus surgery & 9 & 9 & \\
\hline Ligaments reconstruction & 2 & 5 & \\
\hline Distal patella realignment & 2 & 4 & \\
\hline Articular fracture & 2 & 3 & \\
\hline Patient status & & & NS \\
\hline Normal & 29 & 30 & \\
\hline Overweight & 40 & 39 & \\
\hline Obesity & 23 & 23 & \\
\hline Morbid obesity & 8 & 8 & \\
\hline Charnley classification & & & NS \\
\hline A & 17 & 39 & \\
\hline B & 74 & 56 & \\
\hline $\mathrm{C}$ & 9 & 5 & \\
\hline Aetiology & & & NS \\
\hline Medial OA grade 2 & 8 & 6 & \\
\hline Medial OA grade 3 & 63 & 59 & \\
\hline Medial OA grade 4 & 10 & 10 & \\
\hline Lateral OA grade 2 & 0 & 0 & \\
\hline Lateral OA grade 3 & 9 & 11 & \\
\hline Lateral OA grade 4 & 0 & 1 & \\
\hline Posttraumatic OA & 3 & 3 & \\
\hline Rheumatoid Arthritis & 4 & 5 & \\
\hline Patellofemoral OA & 3 & 5 & \\
\hline
\end{tabular}

Table 1. (continued)

\begin{tabular}{|c|c|c|c|}
\hline & Cemented & Cementless & $p$ value \\
\hline \multicolumn{4}{|l|}{ Surgical approach } \\
\hline ATT osteotomy & 1 & 0 & \\
\hline Anterolateral & 14 & 11 & \\
\hline Anteromedial & 85 & 89 & \\
\hline HKA angle pre-op & & & NS \\
\hline$<160$ & 2 & 0 & \\
\hline $160 / 164$ & 6 & 17 & \\
\hline $165 / 169$ & 28 & 27 & \\
\hline $170 / 173$ & 35 & 19 & \\
\hline $174 / 176$ & 8 & 12 & \\
\hline $177 / 179$ & 4 & 1 & \\
\hline 180 & 6 & 6 & \\
\hline $181 / 183$ & 1 & 2 & \\
\hline $184 / 188$ & 6 & 2 & \\
\hline $189 / 192$ & 3 & 4 & \\
\hline$>193$ & 1 & 6 & \\
\hline Pre-operative range of motion & & & NS \\
\hline$>137$ & 34 & 34 & \\
\hline $129 / 136$ & 14 & 11 & \\
\hline $121 / 128$ & 12 & 8 & \\
\hline $113 / 120$ & 15 & 10 & \\
\hline $105 / 112$ & 8 & 11 & \\
\hline $97 / 104$ & 1 & 5 & \\
\hline$<97$ & 1 & 12 & \\
\hline NR & 16 & 9 & \\
\hline Flexum deformity pre-op & & & NS \\
\hline$>15$ & 4 & 11 & \\
\hline $11-15$ & 13 & 20 & \\
\hline $5-10$ & 28 & 25 & \\
\hline$<5$ & 47 & 44 & \\
\hline NR & 7 & 0 & \\
\hline
\end{tabular}


at surgery is 73.16 years (44-83). Ten patients (10.6\%) died of causes unrelated to knee surgery, six (6.4\%) were definitely lost to follow up. We consider as lost to follow up, patients we were not able to follow at the regular outpatient visit, or patients we were not able to contact by phone or post mail. The mean follow-up (average time, in years, between surgery and latest revision) is $13.66(14-12)$. Primary OA was the most frequent aetiology, $81 \%$ of medial $\mathrm{OA}$ in varus knee and $9 \%$ lateral OA in valgus deformity. Fifteen patients had previous surgery concerning meniscus, patella and ligament. According to Charnley classification, 17 had only one joint involved. One third had a normal weight and one third were obese. Anteromedial approach was used in 85 cases, in one case we had to do an ATT osteotomy. The mean gain of the Knee Society score was 57.2 for knee score and 41.6 for knee function. The post-operative range of motion is correlated to the pre-operative range of motion (Table 2). One patient developed a late infection at four years post-operative and underwent a global revision.

Six patients were revised for loosening of one or both components. The mean interval between index surgery and revision was 5.4 years (1-13 years). (Table 3) Details are as follows:

- three cases $(3 \%)$ in three patients with isolated aseptic loosening of the tibia component;

- three cases (3\%) in three patients with bipolar (femur and tibia) aseptic loosening;

- no isolated aseptic loosening of the femoral component.

Three other revisions were performed for:

- one case of unexplained pain;

- one case of stiffness;

- one case of periprosthetic fracture.

\section{Cementless series (Table 1)}

Among 635 cementless New Wave TKA ${ }^{\mathrm{TM}}, 100$ operations in 95 patients ( 57 females) have been included. Five patients $(5.3 \%)$ died of causes unrelated to knee surgery, seven (7.4\%) were lost to follow up. The mean age at surgery was 72.25 years (51-83). The mean follow-up was 12.1 years (11-13). Primary OA was the most frequent pathology $75 \%$ of medial $\mathrm{OA}$ in varus knee and $12 \%$ lateral $\mathrm{OA}$ in valgus deformity. Twenty-one patients had previous surgery concerning meniscus, patella and ligament. According to Charnley classification, 39 patients had only one joint involved. One third had a normal weight and one third were obese. Anteromedial approach was used in 89 cases, lateral approach in 11 cases. The mean gain of Knee Society Score was 55.1 for knee score and 50.8 for knee function (Table 2). The range of motion is correlated to the pre-operative range of motion (Table 2). No infections occurred in this series.

Two cases $(2 \%)$ in two patients were revised for aseptic loosening of the tibial component at one and two years after index surgery (Table 3).

Four patients underwent a minor revision: one arthroscopic synovectomy for a clunck syndrome, three arthroscopic lysis for stiffness.
Table 2. Correlation of pre- and post-operative range of motion in cemented and cementless series.

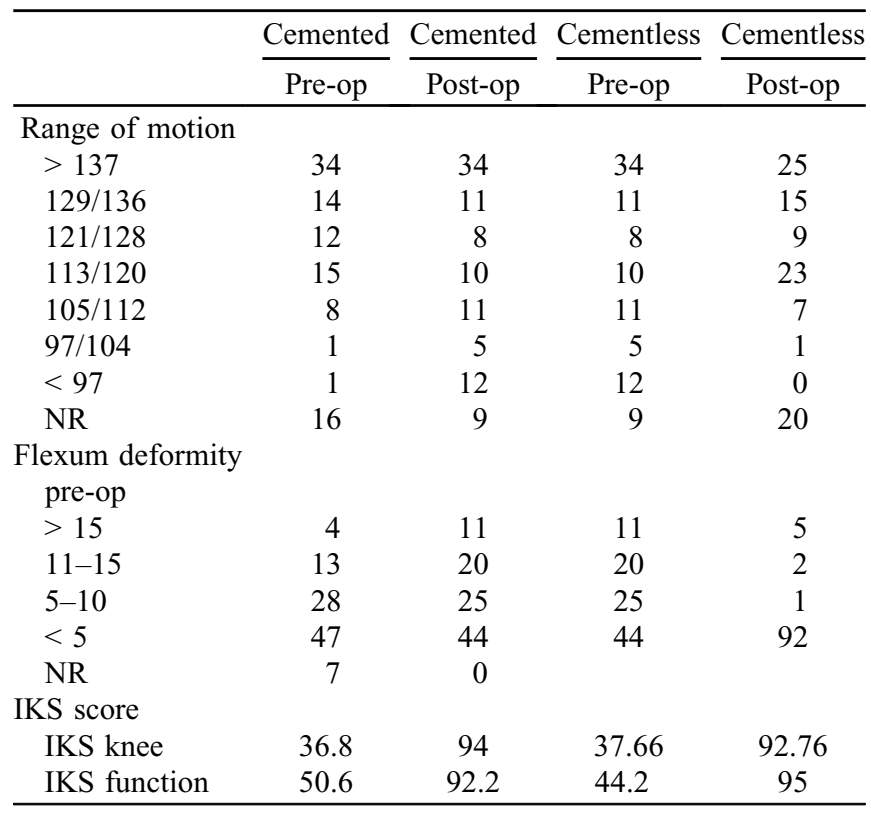

Five patients suffered a periprosthetic fracture (four femur, one tibia). Open fixation with a locking plate was performed in two cases, a global revision in three cases.

\section{Survival curve (Figure 5)}

With the endpoint being revision of one or both components, survival probabilities at 11 years of follow-up were:

- cemented group: 90.2\% CI95\% [81.9-94.8] (78 arthroplasties still included in the analysis);

- cementless group: 95.4\% CI95\% [88.1-98.2] (69 arthroplasties still included in the analysis).

The difference between each group was not significant $(p=0.32)$.

\section{Discussion}

With a survival probability of $90.2 \%$ (cemented version) and $95.4 \%$ (cementless version), this total knee prosthesis performs as intended in primary total knee arthroplasty. We have observed more loosening in the cemented series than in cementless (six cases vs. two cases). Actually due to the small size of the sample the difference is not statistically significant. However, our feeling is that we have observed less fixation failure with the cementless component than with the cemented one. On the other hand, we have observed more periprosthetic fractures with the cementless TKA but differences are not significant. This is one of the weaknesses of this study which is a retrospective nonrandomized cohort. No statistical differences could be found between cemented and cementless implants. The strengths of the study are length of follow-up 
Table 3. Complications.

\begin{tabular}{lcc}
\hline & Cemented & Cementless \\
\hline $\mathrm{ROM}<90^{\circ}$ at three months (treated by manipulation under anesthesia) & 9 & 6 \\
Clunk (treated by arthroscopic synovectomy) & 1 & 1 \\
Stiffness (treated by arthroscopic arthrolysis) & 1 & 3 \\
Infection (treated by global revision) & 6 & 0 \\
Loosening (treated by revision) & 1 & 2 \\
Stiffness (treated by global revision) & 1 & 0 \\
Pain (treated by global revision) & 1 & 3 \\
Periprosthetic fracture (treated by global revision) & 0 & 2 \\
Periprosthetic fracture (treated by internal fixation) & & 3 \\
\hline
\end{tabular}

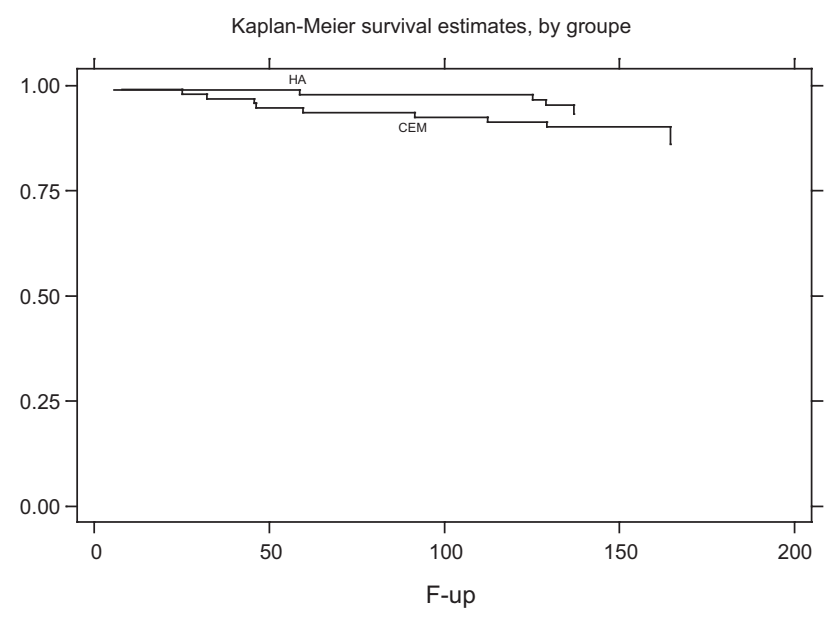

Figure 5. Survival curve.

and comparison of fixation mode between two series which are similar from an epidemiologic point of view.

\section{Cementless fixation}

Historically TKA components were fixed to the bone thanks to a cementing technique as used in the Total Hip Arthroplasty (THA). Satisfying mid-term results with cementless fixation in THA, in the early 1980s, had led surgeons to introduce this fixation mode [3] (PCA group - Hungerford, Kenna, Krackow).

Cementless fixation was obtained by a macroporous coating with two layers of metallic beads. To ensure immediate stability of the implant, the authors also introduced an original ancillary device to get the closest contact between the implant and the host bone. Early results were excellent but failures occurred mainly due to the beads' release and migration in the prosthetic joint [3-5]. Miller and Gallante [10] addressed the metallic failures of the PCA TKR by using a titanium fibre-mesh coating $\left(\right.$ Zimmer $\left.^{\mathrm{TM}}\right)$. It has been suggested that the poor design of these early components could be responsible for these bad outcomes. Previous failures have led the surgeons to shift to a cemented fixation as demonstrated in the National Joint Registry data $[11,12]$. Interest in cementless fixation in TKA has increased in many parts of the world and especially in France.
The theoretical advantages of cementless TKA are bone stock preservation, cement debris protection and the potential to achieve biologic fixation of the implant to the bone. Cementless implants rely on a porous or roughened surface to facilitate bone formation. The initial stability obtained at surgery influences long-term fixation [13], which is important to prevent micromotion compromising the chance of achieving osseointegration.

\section{Added value of a double-layer titanium and hydroxyapatite (HA) coating}

Hydroxyapatite (HA) is a bioactive coating added to the metal of a cementless TKA. The new wave cementless implant is made of cobalt chromium alloy. It can be used with or without cement. In the cementless version, the implant is totally coated under vacuum with a double layer of titanium spray $(120 \mu \mathrm{m})$ covered with HA $(80 \mu \mathrm{m})$. HA has been shown to accelerate bone integration and so to decrease micromotion of the tibia component and to increase fixation of both components [14-16]. Cross and Parish [14] reported a series of 1000 patients with HA-coated cementless TKA at nine years' follow-up with a $0.5 \%$ revision rate for aseptic loosening. Epinette and Manley [6] found a survivorship of $98.14 \%$ at a mean follow-up of 11.2 years (endpoint is mechanical failure) in 146 primary TKA treated with an HA-coated cementless TKA. Voigt and Mosier [17] in a meta-analysis of 926 arthroplasties conclude that HA-coated implants may provide better durability than other forms of fixation including cemented TKA.

With a 95.4\% CI95\% [88.1-98.2] (endpoint: revision of one or both components), our results are consistent with results previously reported.

\section{New technologies in cementless fixation}

Trabecular metal is a biomaterial made of Tantalum with porosity and mechanical properties resembling trabecular bone [18]. Other new concepts are introduced in cementless fixation: BIOFOAM (MicroPort Orthopedics Inc) is one of the several titanium foams created by various manufacturers. Additive manufacturing using electron beam melting (EBM) is also coming to orthopaedic implants. 
Table 4. Randomized controlled trials comparing cemented and cementless fixation (survivorship endpoint $=$ revision for all causes).

\begin{tabular}{lccccccc}
\hline \multicolumn{1}{c}{ Author, year } & $\begin{array}{c}\text { Study } \\
\text { type }\end{array}$ & $\begin{array}{c}N \\
\text { prosthesis }\end{array}$ & $\begin{array}{c}\text { Follow-up } \\
\text { (year) }\end{array}$ & $\begin{array}{c}\text { Cemented } \\
(\%)\end{array}$ & $\begin{array}{c}\text { Hybrid } \\
(\%)\end{array}$ & $\begin{array}{c}\text { Cementless } \\
(\%)\end{array}$ & Cementless + HA (\%) \\
\hline Kim et al. [20], 2014 & RCT & 160 & 17 & 100 & & 100 & NS \\
Beaupré et al. [21], 2007 & RCT & 70 & 5 & 97.5 & & & NS \\
Baker et al. [22], 2007 & RCT & 269 & 10 & 91.7 & & 93.3 & NS \\
Parker et al. [23], 2001 & RCT & 100 & 14 & & 65.0 & 50.0 & NS \\
\hline
\end{tabular}

\section{Rotating tibial plate}

Rotating tibial components were introduced 20 years ago in order to decrease the stresses at the interface between implant and bone. Buechel et al. [19] reported in 2001 a series of 140 New Jersey LCS TKR at 16 years' follow-up with a survivorship of $100 \%$. One of the main complications of this kind of device was dislocation or the so-called spinout of the rotating PE insert. To prevent this particular complication, a New Wave polyethylene insert is characterized by a specific design to allow a total tibio-femoral congruence in the frontal and sagittal plane from full extension to full flexion. It can rotate over the highly polished tibia tray thanks to a $29 \mathrm{~mm}$ long peg freely rotating inside the tibia tray. The stabilizing device is $15.5 \mathrm{~mm}$ high and articulates to the inter-condylar femoral cage (Figure 3). In our series we did not observe such a complication.

\section{Cemented versus cementless fixation}

In our series, even though the survival probability seems to be better in the cementless group, no statistical differences could be found between cemented and cementless New Wave $\mathrm{TKA}^{\mathrm{TM}}$. These results are consistent with those of randomized controlled trials [21, 22] or series with long-term follow-up [23] comparing cemented and cementless fixation (Table 4) and Gandhi et al. [24] in his meta-analysis or, Arnold et al., in his systematic literature review analysis [25].

According to our results we can conclude that cementless fixation has demonstrated its reliability. Mid- and long-term results are similar to cemented fixation which is still the most common method used throughout the world. This fact seems paradoxal when comparing the fixation mode between hip and knee replacement.

\section{Conclusion}

With a survival probability of $90.2 \%$ (cemented version) and $95.4 \%$ (cementless version), New Wave $\mathrm{TKA}^{\mathrm{TM}}$ total knee prosthesis performs as intended in primary total knee arthroplasty. No statistical differences could be found between cemented and cementless implants.

\section{References}

1. NICE (2002) Technology Appraisal Guidance TA44: guidance on the use of metal on metal hip resurfacing arthroplasty.
2. NICE (2014) Technology Appraisal Guidance 304: total hip replacement and resurfacing arthroplasty for end-stage arthritis of the hip.

3. Hungerford DS, Kenna RV, Krackow KA (1982) The porouscoated anatomic total knee. Orthop Clin North Am 13(1), $103-122$.

4. Dodd CA, Hungerford DS, Krackow KA (1990) Total knee arthroplasty fixation. Comparison of the early results of paired cemented versus uncemented porous coated anatomic knee prostheses. Clin Orthop Relat Res 260, 66-70.

5. Ebert FR, Krackow KA, Lennox DW, Hungerford DS (1992) Minimum 4-year follow-up of the PCA total knee arthroplasty in rheumatoid patients. J Arthroplasty 7(1), 101-108.

6. Epinette JA, Manley MT (2007) Hydroxyapatite-coated total knee replacement: clinical experience at 10 to 15 years. J Bone Joint Surg Br 89(1), 34-38.

7. Caton JH, Prudhon JL, Aslanian T, Verdier R (2016) Patellar height assessment in total knee arthroplasty: a new method. Int Orthop 40(12), 2527-2531.

8. Prudhon JL, Caton JH, Aslanian T, Verdier R (2017) How is patella height modified after total knee arthroplasty? Int Orthop, DOI: 10.1007/s00264-017-3539-6.

9. Charnley J (1979) Numerical grading of clinical results, in Low friction arthroplasty of the hip. Berlin, Springer-Verlag pp. 20-24.

10. Nilsson KG, Kärrholm J, Linder L (1995) Femoral component migration in total knee arthroplasty: randomized study comparing cemented and uncemented fixation of the Miller-Galante I design. J Orthop Res 13(3), 347-356.

11. Graves S, Davidson D, Tomkins A et al. (2010) Australian Orthopaedic Association. National Joint Registry. Annual report, 2010, http://www.dmac.adelaide.edu.au/aoanjrr/documents/ aoanjrrreport_2010.pdf (accessed on 18 April 2012).

12. Ellams D, Forsyth O, Mistry A et al. (2010) National Joint Registry for England and Wales: 7th Annual Report, 2010, http:// www.njrcentre.org.uk/NjrCentre/Portals/0/NJR\%207th\% 20Annual\%20Report\%202010.pdf (accessed on 18 April 2012).

13. Berahmani S, Janssen D, Wolfson D et al. (2015) The effect of surface morphology on the primary fixation strength of uncemented femoral knee prosthesis: a cadaveric study. J Arthroplasty 30, 300-307.

14. Cross MJ, Parish EN (2005) A hydroxyapatite-coated total knee replacement: prospective analysis of 1000 patients. J Bone Joint Surg Br 87-B, 1073-1076.

15. Nelissen RG, Valstar ER, Rozing PM (1998) The effect of hydroxyapatite on the micromotion of total knee prostheses. A prospective, randomized, double-blind study. J Bone Joint Surg Am 80-A, 1665-1672.

16. Tai CC, Cross MJ (2006) Five- to 12-year follow-up of a hydroxyapatite-coated, cementless total knee replacement in young, active patients. J Bone Joint Surg Br 88-B, 1158-1163. 
17. Voigt JD, Mosier M (2006) Hydroxyapatite (HA) coating appears to be of benefit for implant durability of tibial components in primary total knee arthroplasty. Acta Orthop 82(4), 448-459.

18. Dunbar MJ, Wilson DA, Hennigar AW et al. (2009) Fixation of a trabecular metal knee arthroplasty component. A prospective randomized study. J Bone Joint Surg Am 91-A, $1578-1586$.

19. Buechel FF Sr., Buechel FF Jr., Pappas MJ, D'Alessio J (2001) Twenty-year evaluation of meniscal bearing and rotating platform knee replacements. Clin Orthop Relat Res 388, 41-50.

20. Kim YH, Park JW, Lim HM, Park ES (2014) Cementless and cemented total knee arthroplasty in patients younger than fifty five years. Which is better? Int Orthop 38(2), 297-303.

21. Beaupré LA, Al-Yamani M, Huckell JR, Johnston DW (2007) Hydroxyapatite-coated tibial implants compared with cemented tibial fixation in primary total knee arthroplasty. A randomized trial of outcomes at five years. J Bone Joint Surg Am 89(10), 2204-2211.

22. Baker PN, Khaw FM, Kirk LM, Esler CN, Gregg PJ (2007) A randomised controlled trial of cemented versus cementless press-fit condylar total knee replacement: 15-year survival analysis. J Bone Joint Surg Br 89(12), 1608-1614.

23. Parker DA, Rorabeck CH, Bourne RB (2001) Long-term followup of cementless versus hybrid fixation for total knee arthroplasty. Clin Orthop Relat Res 388, 68-76.

24. Gandhi R, Tsvetkov D, Davey JR, Mahomed NN (2009) Survival and clinical function of cemented and uncemented prostheses in total knee replacement: a meta-analysis. J Bone Joint Surg Br 91(7), 889-895.

25. Arnold JB, Walters JL, Solomon LB, Thewlis D (2013) Does the method of component fixation influence clinical outcomes after total knee replacement? A systematic literature review J Arthroplasty 28(5), 740-746. 